\title{
Power Flow Management of Grid Connected Micro-grid
}

\author{
P Aruna Jeyanthy, Elstin Prees, K Saravanakumar
}

\begin{abstract}
In this paper, a novel control method for the power flow management of grid connected with transformer-battery based system including bidirectional (BL) DC-DC converter is presented. The objective of this proposed system is to satisfy the load demand and control the power flow management from the different sources. A BL boost converter is used to boost the power from the wind and connected with battery charging or discharging. Rectifier is used here to convert $A C$ to $D C$ and that the received DC supply gets boost up by $D C$-DC boost converter. $A$ $B L$ converter is used for supplying loads. The advantage of the proposed work is simple in operation, minimizes the losses and feeds the extra amount of power into the grid. The battery can be charged from the grid also whenever it is required.
\end{abstract}

Keywords : DC micro grid, DC-DC converter, Energy storage system, Simulation.

\section{INTRODUCTION}

In this paper the development and control of the micro grid is done in simulink, in order to know the consequences in the real time applications. A prototype hardware model is also demonstrated representing the development and control of Micro-grid. The supply is taken from two sources namely energy storage battery and from the wind power. To do the simulink, the capacity of the wind power is taken from a $12 \mathrm{~V}$, $50 \mathrm{amps}$ transformer and is considered as fixed instead of the wind power effect. DC-DC BL converter is used here; if the grid didn't gets supply from the wind then the battery supplies the power to the grid with the help of DC-DC BL converter. This $12 \mathrm{~V}$ transformer is Ac supply and it will be converted into DC with the help of rectifier. Battery storage capacity is also $12 \mathrm{~V}$. Thus the two sources used in the work are the $12 \mathrm{~V}$ battery and $12 \mathrm{~V}, 50 \mathrm{Amps}$ transformer. The Simulink details are given clearly in the following sections.

\section{LITERATURE REVIEW}

The increase in penetration of renewable energy has created challenges to the safe and reliable operation of micro-grid. Design of micro-grid system is done in matlab simulation, but no hardware part is done, because its cost is high [1-12]. In design and simulation of stand-alone micro-grid with energy storage system, they used solar and battery to supply grids [3]. In [2], wind, PV and battery hybrid system is used, by this more supplies can be obtained but the cost is high. In this

Revised Manuscript Received on December 15, 2019.

* Correspondence Author

P Aruna Jeyanthy*, EEE department, Kalasalingam University, Srivilliputhur, India. Email: arunadarwin@ gmail.com

Elstin Prees, EEE department, Kalasalingam University, Srivilliputhur, India. Email: elstinprees2@gmail.com

K Saravanakumar, EEE department, Kalasalingam University, Srivilliputhur, India. Email: klu9915006034@ gmail.com proposed work prototype hardware demonstration and the simulation for the control of power flow management in micro-grid is presented. The architecture for the control of power flow management in grid connected micro-grid with energy storage battery is discussed below:

\section{BLOCK DIAGRAM AND DESCRIPTION}

The block diagram of the proposed work is given in the Fig. 1. The two sources are connected to the load through a DC micro grid. The working flow for the control of the power flow management is represented in the schematic diagram. In this working process $12 \mathrm{~V}, 50 \mathrm{amps}$ transformer is used. Transformer is AC supply; this AC supply will be converted into DC with the help of Rectifier. This converted DC will be boosted by DC -DC Boost converter. By boosting the DC supply minimum $24 \mathrm{~V}$ will be generated to the grid. Battery storage capacity is $12 \mathrm{~V}$. When there is no supply from transformer this $12 \mathrm{~V}$ battery will give supply to grid. This $12 \mathrm{~V}$ also will be boosted and grid will get $24 \mathrm{~V}$. By this we can satisfy the load demand

\section{A. Transformer}

Transformer is an electrical device that is used to raise or lower voltages (V) and currents (I). Transformers are used to boost voltages levels to decrease the line loses during transmission. Transformer is needed for efficient transmission of electricity.

\section{B. Rectifier}

Rectifier will convert AC i.e. alternating current to DC i.e. direct current. Here rectifier is needed because this project needs DC output from Transformer. Transformer is AC supply.

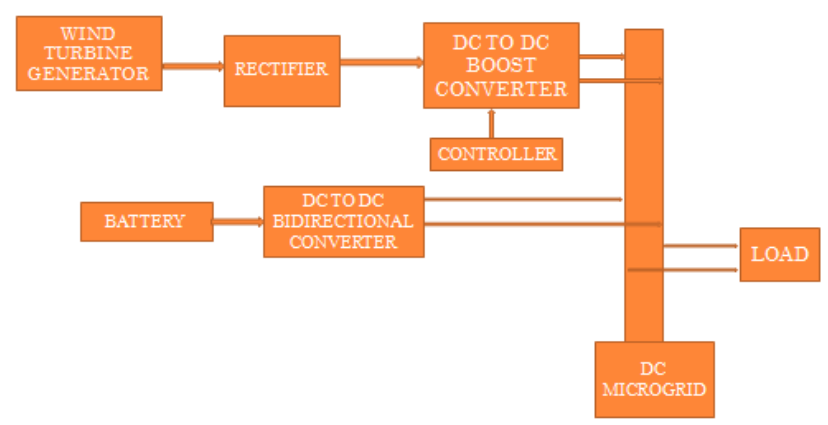

Fig. 1. Development and Control of Micro-grid

Published By: 


\section{DC to DC Boost Converter}

Here the boost converter is a DC to DC converter with an output voltage greater than the source voltage. This converter will boost the $12 \mathrm{~V}$ tapped from the transformer to the output voltage of minimum $24 \mathrm{~V}$ to maximum $36 \mathrm{~V}$. As said the micro-grid, which is a small-scale power grid, here can operate independently or collaboratively. Also the received DC supply from both the sources will be given to grid, which will supply the load. In this work, the bidirectional DC-to-DC converter allows power flow in both forward and reverse directions.

\section{SIMULATION RESULTS AND DISCUSSIONS}

The simulation work is carried on step by step procedure. Initially with the bidirectional converter, the micro grid works for the power flow management for the two generating sources namely the solar and the wind power source. The output for the given simulink in represented in Fig. 3. It shows the voltage and the current wave variation for the applied DC load.

The second step is carried out for the microgrid with the battery system, to deliver the continuous supply for the power flow management. The simulink schematic diagram is system with the battery function is represented in Figure 5. As the wind power is variable in nature, the three phase ac power

Battery storage capacity is $12 \mathrm{~V}$. When there is no supply from transformer this $12 \mathrm{~V}$ battery will give supply to grid. This $12 \mathrm{~V}$ also will be boosted and grid will get $24 \mathrm{~V}$. By this we can satisfy the load demand. The simulink is done for the $12 \mathrm{~V}$ battery boosted with the grid to get the output for $12 \mathrm{~V}$.

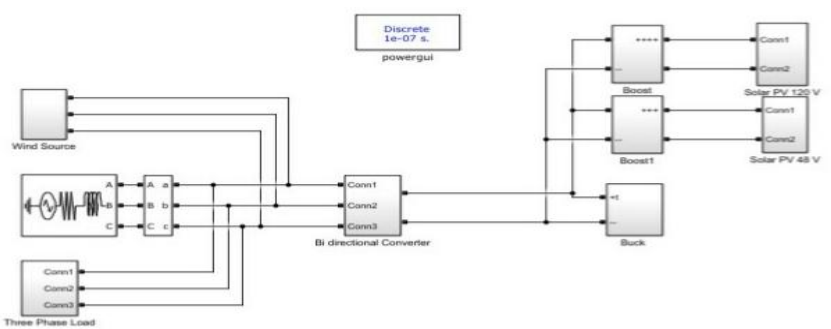

Fig. 2. Simulink diagram with the solar and wind power micro grid

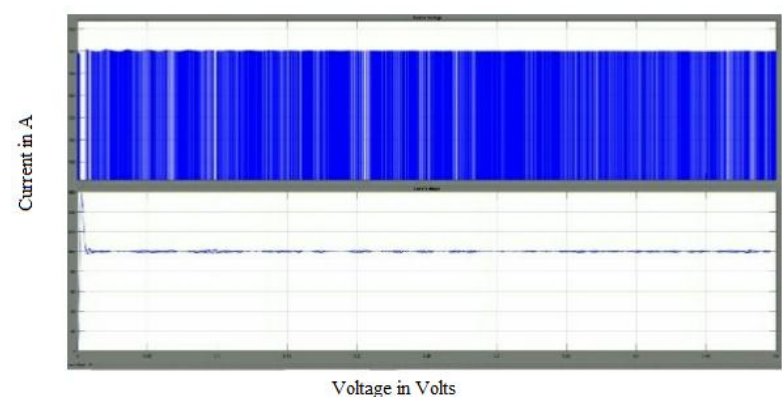

Fig. 3. Output voltage and current for the given DC load simulink diagram is represented in the below Fig. 2. The represented in Fig. 4. The output voltages for the complete is represented in that figure.

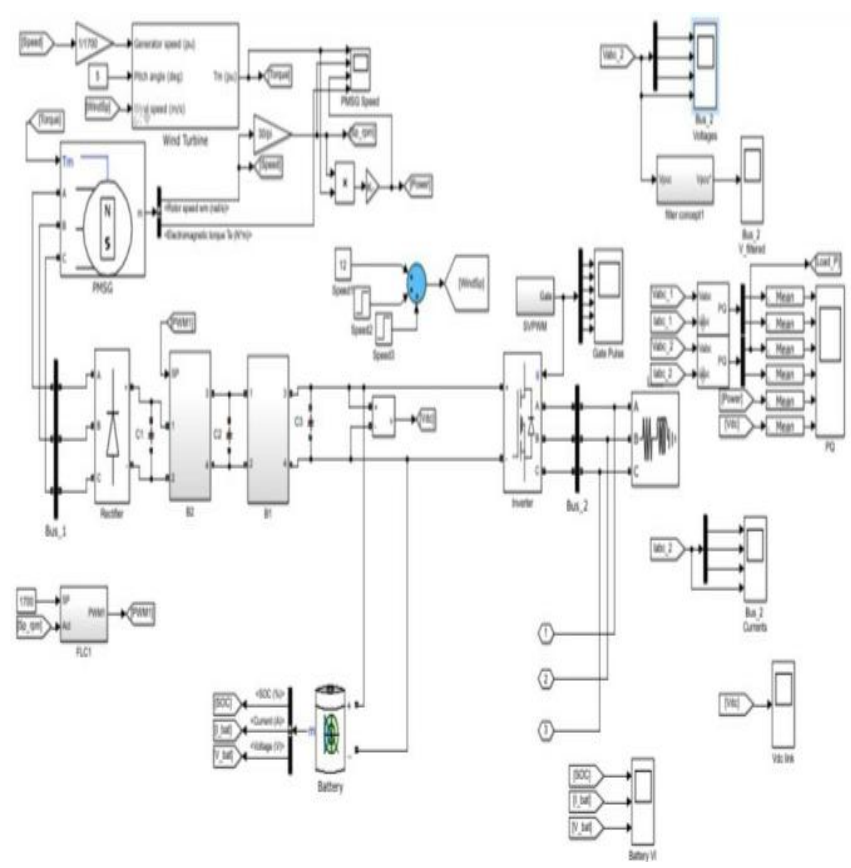

Fig. 4. Simulink diagram with battery system

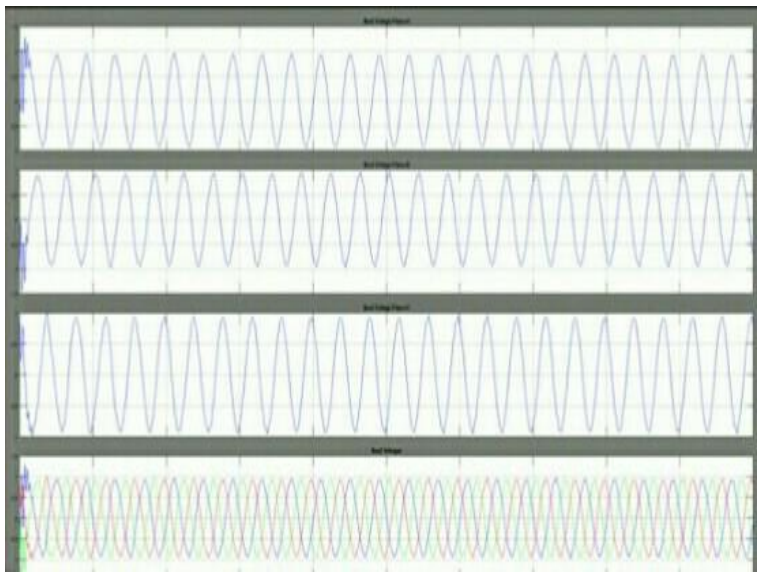

Fig. 5: Three phase output voltages from the wind turbine

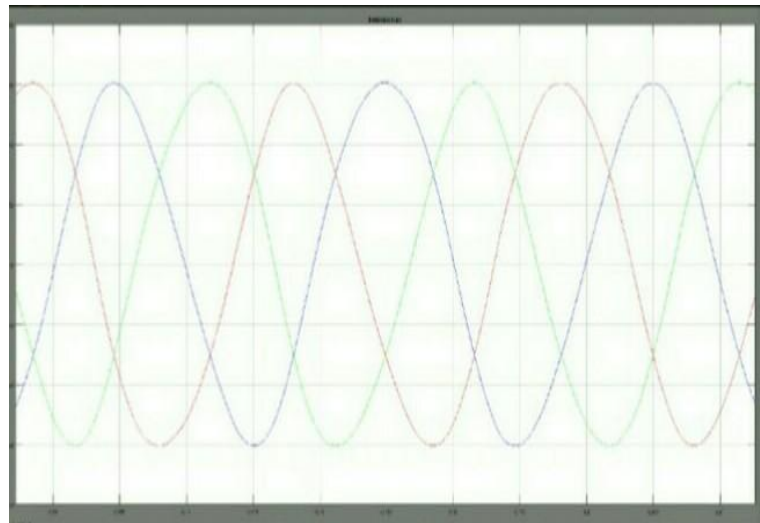

Fig. 6. Three phase reference current used by the Bidirectional Converter

ublished By:

Blue Eyes Intelligence Engineering 


\section{HARDWARE IMPLEMENTATION}



Fig. 7. Prototype of the proposed system

While charging mode the battery will get supply from $12 \mathrm{~V}$ transformer, but this transformer will give $24 \mathrm{~V}$ battery capacity is $12 \mathrm{~V}$ so, we are using buck converter it will buck that $24 \mathrm{~V}$ into $12 \mathrm{~V}$ and supply to battery. In this method battery will be charged and grid will get supply from transformer. While discharging mode battery will give supply to grid, when there is no supply from transformer. Transformer will give $28 \mathrm{~V}$ to grid and remaining will be given to battery, but battery will give all $30 \mathrm{~V}$ to grid.

\section{CONCLUSION}

The development and control of a micro-grid is presented in this paper. Matlab simulink work is done to simulate the micro-grid. The work is also clearly demonstrated with a hardware setup for further processing.

\section{REFERENCES}

1. Anderson, G., Donalek, P., Farmer, R., Hatziargyriou, N., Kamwa, I., \&Kundur, P. (2005, October 31). Causes of the 2003 major grid blackouts in North America and Europe, and recommended means to improve dynamic system performance. IEEE Transactions on Power Systems, 20(4), 1922 - 1928. Retrieved September 16, 2017

2. Chen, L., \&Hongkun Chen, J. Y. (20 January 2017). Comparison of Superconducting Fault Current Limiter and Dynamic Voltage Restorer for LVRT Improvement of High Penetration Microgrid. IEEE Transactions on Applied Superconductivity, 27(4), 1-7.

3. Costabeber, A., Tenti, P., \&Mattavelli, P. (10 January 2011). Surround control of distributed energy resources in micro-grids. Sustainable Energy Technologies (ICSET), 2010 IEEE International Conference on, $1-6$.

4. Fong, Y. C., Cheng, K. W., Ye, Y., \& Chan, Y. C. (2017). Centralized Regulation Scheme for a Parallel-Mode Switched-Capacitor Converter System With Simple Unit Commitment. Yat Chi Fong; KaWai Eric Cheng; Yuanmao Ye; Yin Chun Chan, 64(8), 6149 - 6158.

5. Guerrero, J., Vicuna, L. d., Matas, J., Castilla, M., \&Miret, J. (2004, September 03). A wireless controller to enhance dynamic performance of parallel inverters in distributed generation systems. IEEE Transactions on Power Electronics, 19(5), 1205 - 1213. Retrieved September 14, 2017

6. H.K. Kang, S. A. (02 October 2009). A new method to determine the droop of inverter-based DGs. Power \& Energy Society General, 1-6.

7. Kim, J.-W., Choi, H.-S., \& Cho, B. H. (2002). A novel droop method for converter parallel operation. IEEE Transactions on Power Electronics, 17(1), 25 - 32

8. Lombardi, P. (21 February 2013). Optimal storage capacity within an autonomous micro grid with a high penetration of Renewable Energy Sources. Innovative Smart Grid Technologies (ISGT Europe), 2012 3rd IEEE PES International Conference

9. Liu Jizhen. The basic problem of large-scale new energy and electric power safety and efficient use of $[\mathrm{J}]$. Proceedings of the CSEE, 2013,16:1-8+25. [12] Han Kun, Li Jun, Li Yuling, et al. A novel control strategy of direct-drive PMSG wind generation MPPT based on experimental imitation platform $[\mathrm{J}]$. ActaEnergiae Solaris Sinica, 2010,11:1497 -1502.

10. Zhao Rende, Wang Yongjun, Zhang Jiasheng. Direct drive permanent magnet synchronous wind power system maximum power tracking control [J]. Proceedings of the CSEE, 2009,27:106-111.

11. Liu Bangyin, DuanShanxu, Kang Yong. Modeling and analysis of the characteristics of PVmodule with partial shading [J].ActaEnergiae Solaris Sinica, 2008,02:188-192.

12. Wang Yalin, Wen Fang. Charging Strategy Research of Super Capacitor[J]. Mechanical Engineering and Automation, 2012,05:170-171.

\section{AUTHORS PROFILE}

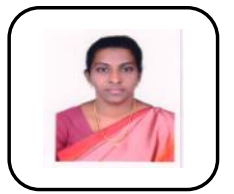

P Aruna Jeyanthy completed her $\mathrm{PhD}$ degree in the year 2011, in Anna University, Chennai, India. She is one of a senior member in the IEEE professional membership society. At present she is working in Kalasalingam Academy of Research and Education.

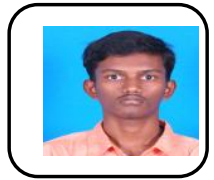

Elstin Prees is the B.Tech final year student in EEE of Kalsalingam Academy of Research and Education. He is passionate in learning things with real time demonstrations

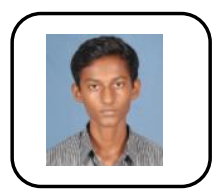

K Saravanakumar completed his under graduation B.Tech degree in Electrical and Electronics Engineering in the year 2019 in Kalasalinagm Academy of Research and Education, Srivilliputhur, India. He is interested in electrical machines and power systems. 